\title{
Left Ventricular Pseudoaneurysms In A Young Patient: A Case Report
}

\author{
Dr. B. Koirala*
}

\section{Abstract}

Left ventricular aneurysm occurs most commonly as a consequence of myocardial Infarction. Congenital Left Ventricular aneurysms occurs rarely as diverticuli of the apex, as a part of a syndrome of congenital defects or following myocardial infarction in children with anomalous origin of coronary arteries, Post-traumatic left ventricular ancurysms are also reported in literature. Chronic infections like tuberculosis with arteritis is also reported as one of the causative factor. Here we report a case of such left ventricular pseudoaneurysms in a young patient probably ischemic in origin. The patient underwent surgery with favorable outcome.

\section{Introduction}

Left ventricular aneurysm occurs most commonly as a consequence of myocardial infaretion. Congenital Left Ventricular aneurysms occurs rarely as diverticuli of the apex, as a part of a syndrome of congenital defects or following myocardial infarction in children with anomalous origin of coronary arteries, Post-traumatic left ventricular aneurysms are also reported in literature, And much rarer are idiopathic left ventricular aneurysms. Chronic infections like tuberculosis, Chagas' disease or sarcoidosis, malformation of arterics or non-specific myocarditis are also reported as possible cause for the condition.

\section{Case Summary}

An twenty year old thin built male from Eastern Terai region of Nepal was to National Heart Centre for further work-up for an incidental finding of a paracardiac shadow on chest $\mathrm{x}$-ray. This was picked up at a local hospital following treatment of pulmonary tuberculosis 8 months back. He had received antitubercular therapy as per WHO guidelines. He had no other significant medical history. He was allergic to Ciprofloxacin. Clinical examination was normal. Hematology showed erythrocyte sedimentation rate of $50 \mathrm{~mm}$ over first hour. Other hematological and biochemical parameters were within normal limits. Chest X-ray showed a well defined shadow along left heart border (fig. 
1). Electrocardiogram showed sinus rhythm with strain pattern in lateral leads. Twodimensional ECHO revealed secular mass at left postero-lateral side of left ventricle with free communication between these two chambers. Left ventriculogram showed a secular aneurysm originating from left ventricle. Coronary angiogram revealed a fusiform aneurysm of proximal second obtuse marginal artery (fig.2).

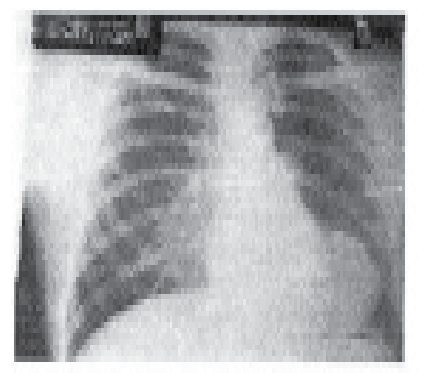

Fin $\mathrm{i}$

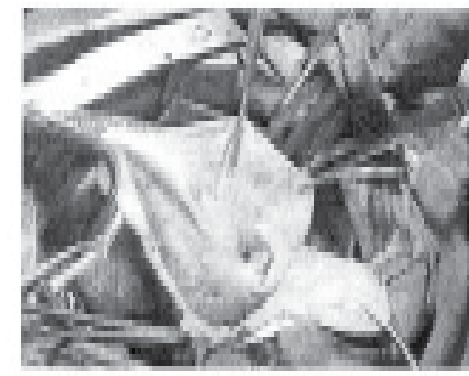

Fin it

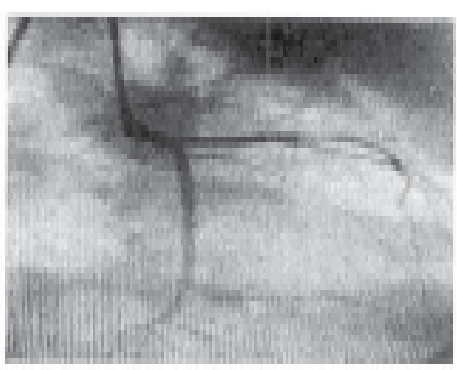

Thin 2

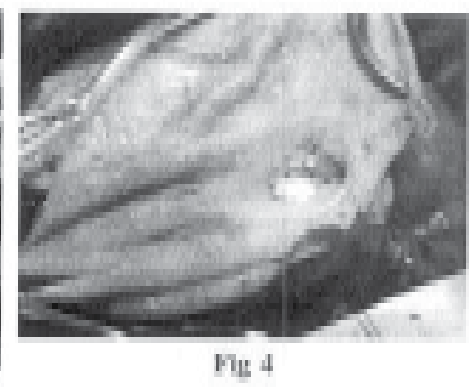

He underwent surgery under cardiopulmonary bypass and cold cardioplegic arrest. Intraoperatively it was found to have fibrinous adhesions between heart and pericardium. Spherical aneurysm arising from the posterior aspect of left ventricle with a narrow communication of about $1 \mathrm{~cm}$ in diameter was noted (fig 3). There was no clot inside the ancurysm. This was thought to be a pseudoaneurysm. The aneurysm wall was dissected and excised leaving a rim. The opening into the left ventricle was repaired using polytetrafluoroethylene (Gore-tex) patch (fig 4). The remnant of the sac was sewn over the patch. Cardiopulmonary bypass was discontinued in usual manner. His postoperative recovery was uneventful with ICU stay of 40 hours. He remained in sinus rhythm and no significant myocardial ischaemia detected on EKG and blood biochemistry, He was discharged on $5^{\text {th }}$ day of operation. Histopathological examination of excised aneurysmal wall showed thin walled fibrous tissue with calcification. No sign of

* Sahid Gangalal National Heart Centre 
chronic inflammation detected. On follow-up after 3 months and one year he had no new complaints, and cardiac work up normal.

\section{Discussion}

Myocardial infarction is the cause of left ventricular aneurysm formation in adult population. However in younger population with left ventricular ancurysm, the etiology is not always certain. Among young patients, the commonest etiology of left ventricular aneurysm is congenital presenting as diverticulum of the apex or as a part of a syndrome of congenital defects. It can also develop following myocardial infarction in children with anomalous origin of coronary arteries ${ }^{1}$. There are reports of left ventricular aneurysm after pericarditis, endocarditis, septicemia following Staphylococcus aureus infection, tumor infiltration or of unknown etiology $2,3,4,5,6,7$. Our patient had history of pulmonary tuberculosis in the recent past with complete treatment. The patient had raised ESR $50 \mathrm{~mm} / 1^{\text {st }}$ hour) which could be due to the chronic infection: tuberculosis. Tuberculosis is reported to develop arteritis and aneurysm formation. This is the most likely cause for embolisation and development of myocardial infarction leading to rupture and pseudoaneurysm formation.

Symptomatically, most of the patients with left ventricular aneurysm in other series presented with arrhythmia or congestive cardiac failure $\mathrm{e}^{8,9,10,11}$. Our patient was asymptomatic at the time of presentation. Two dimensional echocardiography scems to be a good tool for the diagnosis of this condition. However, left ventriculogram with coronary angiogram precisely locate the site of aneurysm formation and coronary artery abnormalities, if present.

Treatment of choice is surgical repair, with favorable outcome in most serics, The histopathological report of the excised sac of our patient could not prove the presence of granulomatous disease except fibrosis, calcification and chronic inflammatory cell infiltration.

This report indicates the possibility of development of left ventricular pscudoaneurysm from chronic inflammatory condition involving the coronary Arteries. 


\section{References}

1. (Dolara A, Distante S, Lagi A et al, Idiopathic aneurysm of the left ventricle, Report of two cases and review of literature. GIHal Cardiol. 1976; 6(6): 1124- 9)

2. de Boer HD, Elzenga NJ, de Boer WJ, Meuzelaar JJ, Pseudoaneurysm of the left ventricle after isolated pericarditis and Staphylococcus aureus sepuicemia, Eur J Cardiothorac Surg 1999; 15:97-99,

3. Frances C, Romero A, Grady D. Left ventricular pseudoaneurysm, J Am Coll Cardiol 1998;32:557-561,

4. Wiegers SE, Plehn JF, Rajail-Khorasani A, et al, Purulent pericarditis and ventricular pscudoancurysm in an intravenous drug abuser. Am Heart J 1988;116(6pt 1): 16351637 ,

5. Lee PJ, Spencer KT, Pscudoaneurysm of the left ventricular free wall caused by tumor infiltration. J Am Soc Eehocardiogr 1999;12;604-606.

6. Sharma SN, Bahl VK, Venugopal P. Left ventricular pseudoaneurysm following Infective endocarditis. Indian Heart J 1991;43:395-396,

7. Detaint D, Messika-Zeitoun D, Goube P, et al. An exceptional eliology of left ventricular ancurysm: type AA amyloidosis. Arch Mal Coeur Vaiss 2003 Apr;96(4): 344-346,

8. Lioulias GN, Kokotsakis JIN, Skouteli EA, Boulafendis DG. Posterior non- ischemic left ventricular aneurysm. Report of 2 surgical cases, J Cardiovasc Surg ( Torino) 2002 Dec;43(6):833-836,

9. Mechmeche R, Boussaada R, Angar H, Cherif A, Farhati A, Drissi MF, False left ventricular aneurysm.report of 5 cases. Tunis Med, 2002 Jul;80(7):416- 419. 
10. Ezzat MA, Abdelmeguid I, Leclere D, Nguyen A, Piwnica A. Left ventricular pscudoaneurysm associated with mitral regurgitation. The Annals of Thoracic Surg. 1991;51:476-478.

11. Rimailho A, Cabrol C, Soyer R, et al. Idiopathic aneurysm of the left ventricle. Apropos of 4 cases operated on with success. Arch Mal Cocur Vaiss. 1981 Apr;7494):443.451, 